\title{
Dialogic Lessons and Triadic Relationship Among Pupils, Learning Topic, and Teacher
}

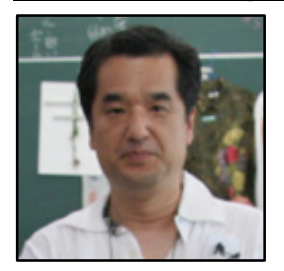

Kiyotaka Miyazaki

Waseda University, Japan

\begin{abstract}
This paper argues that a teacher should and can be not only the organizer of a lesson as well as participant in a dialogue who has the equal right with pupils vis-à-vis the truth of the learning material in order to make lessons dialogic. To analyze such a teacher's way of being in the lesson, the concept of a triadic relationship among pupils, learning material, and a teacher was introduced. The teacher can learn something new in the pupils' learning material as the pupils can do. The teacher can discover an unknown question that she/he does not know its answer or even its existence in pupils' wrong or irrelevant thoughts about the learning material. This sort of teacher's learning makes classroom lessons dialogic as pupils and a teacher exercise the equal rights vis-à-vis the truth of the learning material in the lesson. Here, pupils and teachers learn about the learning material from each other. The importance of this sort of teacher's learning for dialogic lessons has been rarely emphasized in dialogic pedagogy research. These arguments are advanced in this paper based on the analysis of the Japanese elementary teachers' knowledge of practices. This paper focuses mainly on the pedagogical view named Saitou pedagogy developed by Kihaku Saitou and his colleagues, and studies their thoughts and classroom lessons to investigate teacher's work to make lessons dialogic. To provide a theoretical basis for the analysis, theories of dialogue, developmental psychology and dialogic pedagogy were reviewed to understand how these theories had studied the triadic relationship and were compared with Saitou pedagogy. The result demonstrated that Bakhtin's perspective on the dialogic author was useful in analyzing the teacher's way of being in Saitou pedagogy. It was also suggested that Saitou pedagogy's view of the unknown question would give Bakhtinian theories of dialogue a hint for new area of study.
\end{abstract}

Kiyotaka Miyazaki is a professor at the Faculty of Human Sciences, Waseda University, Japan. His research interest is examining the views Japanese teachers' knowledge of practice and making them encounter with theories of dialogism such as Bakhtin, Gadamer and other dialogic pedagogies to discover some universal principles of the dialogic education.

$\cos 0380$

\section{Introduction}

The concept of a triadic relationship among individuals and their shared topic played an important role in the research tradition of dialogism in which the relations between participants of a dialogue and their shared topic is investigated in various forms (Linell, 2009). In more empirically oriented studies, this concept has been emphasized in developmental psychology since the proposal of secondary intersubjectivity by Trevarthen (Trevarthen \& Hubley, 1978). In theories of dialogic pedagogy, a triadic relationship, particularly 


\section{Dialogic Lessons and Triadic Relationship Among Pupils, Learning Topic, and Teacher}

Kiyotaka Miyazaki

among pupils, their learning material, and teachers, has been implicitly presupposed but not explicitly explored as a theme. This paper analyzes some Japanese teachers' thoughts and their classroom lessons to examine how and in what form a triadic relationship among pupils, their learning material, and teachers exists in dialogic lessons and how teacher work in a triadic relationship to make it dialogic.

Why is a triadic relationship among pupils, pupils' learning material, and teachers problematized in this paper? The importance of "collaboration" has been rather common in studies on pupils' learning processes, particularly after the Vygotskian school of learning became popular (Vygotsky, 1978). However, many researchers, particularly in developmental psychology (as discussed in "Developmental Psychology" of the next section), focus only on the collaboration among learners. Even in dialogic pedagogy, the triadic relationship is often presupposed only implicitly. These research trends appear to indicate that teachers and their work are not appropriately featured in studies on learning processes. The fact that we can barely find any description about teachers in the Handbook of Learning Sciences (Sawyer, 2014), or that learning sciences present themselves as learning sciences and not teaching and learning sciences indicates the indifferent attitude toward teachers in studies on learning. Furthermore, when researchers focus on teachers and their work, teachers are considered to be only the organizers of the lessons and not participants who learn pupils' learning material (discussed in "Dialogic Pedagogy" of the next section). I believe that it is necessary to make explicit the triadic relationship that a teacher forms with pupils and their learning material. In particular, it is essential to focus on how the teacher relates to pupils' learning material, that is, how the teacher learns pupils' learning material to understand what occurs in the classroom lessons.

This paper analyzes Japanese teachers' knowledge of practice and lessons as I learned the importance of a triadic relationship for dialogic lessons from teachers' knowledge of practice and lessons. However, this knowledge, based on their practices and reflections about them, remains intuitive and is not yet fully theorized. Although their lessons are dialogic, they do not use the term "dialogue" to characterize their own practices. Therefore, a comparison of Japanese knowledges of practice and studies on dialogism and dialogic pedagogy is necessary to position Japanese knowledge of practice in the research traditions of dialogism and dialogic pedagogy as the first step toward theorizing the Japanese knowledge of practice.

In the Japanese knowledge of practice, I focus on Saitou pedagogy, developed by a practitioner named Kihaku Saitou (1911-1981) and his colleagues. The Japanese government has imposed strict regulations on its public education systems in that the content and order of presentation of pupils' learning materials are prescribed as strict national guidelines for educational courses. However, some teachers started developing their own perspectives on classroom lessons, particularly after the World War II. They formed nongovernmental groups to discuss their lesson practices and develop their perspectives and methods regarding classroom lessons (Shibata, 2009). Saitou pedagogy was developed by one of many such groups, led by Kihaku Saitou.

Kihaku Saitou became an elementary school teacher in 1930 and served as the principal of several elementary schools in the 1950s and 1960s. These schools became famous for their high- quality classroom lessons in the Japanese educational scene. In 1973, he organized a group named KyoujugakuKenkyu-no-Kai, or the Pedagogical Research Group, after his retirement, which included many teachers and some researchers. His perspective was named Saitou pedagogy (Kasahara, 1991). Today, more than thirty years after he passed away, there are certain teachers who still follow his teachings and worked toward developing Saitou pedagogy.

The paper comprises three parts. The first part reviews theories of dialogism, developmental psychology, and dialogic pedagogy to examine how triadic relationship among pupils, their learning material 


\section{Dialogic Lessons and Triadic Relationship Among Pupils, Learning Topic, and Teacher}

Kiyotaka Miyazaki

and teacher, and the relation between pupils' learning material and the teacher have been treated. The second part examines Saitou pedagogy. Saitou's writings are analyzed to examine how Saitou pedagogy thinks about the triadic relationship among pupils, their learning material and the teacher and the relation between the learning material, and teacher. Next, some of their lessons are analyzed to see how their view is materialized in classroom lessons. The third part compares Saitou pedagogy's view and theories of dialogism and dialogic pedagogy to examine the dialogic nature of Saitou pedagogy and what it suggests to develop the theories of dialogic lessons.

\section{Review of Theories on Triadic Relationships}

\section{Dialogism}

First, I examine how the triadic relationships have been studied and how they are considered dialogic in the research tradition of dialogism. The concept of triadic relationship has a critical role in the dialogism studied under the influence of Mikhail Bakhtin, although the term has not been explicitly used in many cases, as observed by Ongstad (2004). Linell (2009), however, used the term triads explicitly and devoted a section in his book to explain the types of triads.

Linell began his arguments by introducing Rommetveit's proposal (2003) of a psychology of the second person. According to Rommetveit, the monologic philosophy of epistemology leads to dichotomy between subjectivism (psychology of the first person) and objectivism (psychology of the third person). Dialogism, as an antidote to monologism, requires the psychology of the second person, "which builds upon the interdependence between 'l' and 'you/thou'" (Linell, 2009, p. 89). However, Linell added, "dialogue is about more than these two parties" (2009, p. 89), and introduced the concept of triads.

Linell inclusively named the concept semiotic triads and classified it into three subtypes. Only one subtype is relevant to the discussion in this paper. The other subtypes include the situational triad, which refers to the relation among Now-Here-I (Buhler, 1934). Linell characterized the triad as coordinates of the communication system (2009, p. 92). This triad may indicate the subject or speaker's location in the dialogue, but it does not refer to the dialogue's structure. Another triad is the abstract semiotic triad, which refers to the relation among word-concept-referent, such as the relation between word, interpretant, and object in Peirce's semiotics (1998). Although this triad describes one aspect of the meaning of speech, it disregards the communicative aspect in which speech has meaning; thus, it is not relevant here. In contrast to these subtypes, pragmatic triad is the relevant subtype, which is the relation among $l$, you, and it-the relations in which I and you share the topic of the dialogue. In explaining this triad, Linell referred to Bühler (1934), Markova (2003, 2006), Du Bois (2007), Tomasello et al. (2005), and Bakhtin. The next section discusses Bakhtin to determine how triadic relations are positioned in his perspective of dialogue.

\section{Bakhtin and the Triadic Relationship}

This discussion on Bakhtin begins with the following quotation:

\footnotetext{
The word (or in general any sign) is interindividual. Everything that is said, expressed, is located outside the "soul" of the speaker and does not belong only to him. The word cannot be assigned to a single speaker. The author (speaker) has his own inalienable right to the word, but the listener also has his rights, and those whose voices are heard in the word before the author comes upon it also have their rights (after all, there are no words that belong to no one). The word is a drama in which three characters participate (it is not a duet, but a trio) (Bakhtin, 1986, pp. 121-122).
} 


\section{Dialogic Lessons and Triadic Relationship Among Pupils, Learning Topic, and Teacher}

Kiyotaka Miyazaki

As Bakhtin declared, the spoken word is not possessed only by the speaker, who has the right to it, but also by others, who also have the right to that word. Here, others here include the listener toward whom the word is oriented and people who previously used and gave voice, or meaning, to the word in the culture before the current speaker used it. Thus, there is a triadic relationship between the speaker, the spoken word, and others. As the third term of the triadic relationship, although the word is shared by the speaker and others, it has different meanings for both. Thus, different meanings meet within the one word. Bakhtin said that not two, but three characters participate in a drama, namely, the speaker, the listener, and the others who use the same word; thus, instead of a triadic relationship, it could be named a quad relationship. However, in this paper, I use the term triadic relationship to show that multiple participants encounter each other in the topic, or in the spoken word, in Bakhtin's quotation; thus, naming the structure Bakhtin described above as triadic relationship presents no problem. Bakhtin also stated that the word is a drama, indicating that the speaker gives variable meaning to the word according to whom it is oriented. Furthermore, the meanings of the spoken word given by others in the past influence how the current speaker uses the word. The speaker appropriates how others used the word and generates her/his use of it. Dynamic interactions occur between the speaker and the listener, and between the speaker and another speaker, and these interactions determine the meaning of the spoken word.

In Bakhtin (1981), the triadic relationship was described in a slightly different manner in that it is formed between the word, the object, and the other word (Bakhtin, 1981, p. 277). In this description, the object that the word conceptualizes is the third term of the triadic relation in the drama. For Bakhtin (1981), the other two triadic terms are the word and the alien word in place of the speaker and others. This structure of triadic relations is basically the same as provided by Bakhtin (1986), considering that the speaker and the other speaker are behind the word and the alien word.

Triadic relationship and dialogue

Thus, when does the triadic relationship become dialogic for Bakhtin? In Bakhtin (1984), he presented the concept of hidden polemic.

[T]he author's discourse is directed toward its own referential object, as is any other discourse, but at the same time every statement about the object is constructed in such a way that, apart from its referential meaning, a polemical blow is struck at the other's discourse on the same theme, at the other's statement about the same object (Bakhtin, 1984, p. 195).

In this excerpt, the author directs her/his discourse toward the referential object. The other directs her/his discourse toward the same object. The triadic relationship here is: the author-<the discourse >object-<the discourse >-the other. These two discourses have different, opposing voices regarding the object; thus, they clash in the object.

However, defining dialogic relation as that in which the speaker's discourse strikes a polemic blow at the other's discourse is not sufficient. Bakhtin did not think that there was no dialogic relation if their opinions were in agreement and no polemic existed between the two parties. Indeed, one important feature of the triadic relationship characterizes Bakhtin's dialogic relation. Although this feature was already presented in Bakhtin's first quotation (1986, pp. 121-122), the following quotation describes it more clearly.

A plurality of independent and unmerged voices and consciousnesses, a genuine polyphony of fully valid voices is in fact the chief characteristic of Dostoevsky's novels. What unfolds in his works is not a multitude of characters and fates in a single objective world, illuminated by a single authorial 


\section{Dialogic Lessons and Triadic Relationship Among Pupils, Learning Topic, and Teacher}

Kiyotaka Miyazaki

consciousness; rather a plurality of consciousnesses, with equal rights and each with its own world, combine but are not merged in the unity of the event (Bakhtin, 1984, p. 6; italics original).

The dialogue's notable feature for Bakhtin is that the plurality of consciousnesses or participants in the dialogue has equal rights. However, equal rights in what? Bakhtin answered, "What monologism is, in the highest sense. A denial of the equal rights of consciousnesses vis-à-vis truth (understood abstractly and systemically)" (Bakhtin, 1984, appendix 2, p. 285).

All participants have equal rights to what is true. One participant's monopolization of that right results in a monologic relation. The important word here is event, about which Emerson, the editor of Bakhtin (1984), made the following comment.

Sobytie (event) and its adjective sobytiinyi (full of event potential) are crucial terms in Bakhtin. At their root lies the Russian word for "existence" or "being" (bytie), and —although the etymology here can be disputed- so-bytie can be read both in its ordinary meaning of "event," and in a more literal rendering as "co-existing, co-being, shared existence or being with another" (Emerson, in Bakhtin, 1984, p. 6, footnote a).

Plural consciousnesses experience the event together and are united in doing so. However, plural consciousnesses do not fuse into one; instead, each retains its uniqueness and a right to what is correct about the event. To be dialogic, participants should retain the equal rights about how they understand the event. Even when participants have the same view of the event and agree with one another, they are still in the dialogic relation if their agreement results from using each one's right to know, and not from onesided use of one participant's right. To briefly summarize Bakhtin's view thus far, the triadic relationship is among a consciousness, an event, and the other consciousness and becomes dialogic when two consciousnesses have the equal rights vis-à-vis the truthfulness of the event.

\section{Bakhtin's dialogic author}

Bakhtin's (1984) remarkable argument is that a novel's author and heroes can have equal rights to the truth of an event. The author produces the novel; thus, giving equal rights to heroes along with the author who produced them seems improbable. Bakhtin holds a contrasting view and distinguishes two types of authors: monologic and polyphonic, or dialogic. The polyphonic author can have equal rights with the heroes to know the events. Bakhtin characterized the polyphonic author as follows.

[T] he author's consciousness does not transform others' consciousnesses (that is, the consciousnesses of the characters) into objects, and does not give them secondhand and finalizing definitions. Alongside and in front of itself it senses others' equally valid consciousnesses, just as infinite and open-ended as itself. It reflects and re-creates not a world of objects, but precisely these other consciousnesses with their worlds, re-creates them in their authentic unfinalizability (which is, after all, their essence) (Bakhtin, 1984, p. 68).

For Bakhtin, Dostoevsky is a polyphonic, or dialogic author, and he compared Dostoevsky with Tolstoy as a monologic author to concretely show how the dialogic author can have equal rights vis-à-vis an event's truth. As an example of a monologic novel, Bakhtin cited Tolstoy's Three Deaths to illustrate how the monologic author treats the three heroes, namely, a rich noblewoman, a coachman, and a tree, by comparing these to Dostoevsky's imaginary case. As for Tolstoy's Three Deaths, Bakhtin first mentioned the relations between the heroes, saying that each hero does not unite with or know anything about the others. Only "the author knows everything about them [three heroes] ..." (Bakhtin, 1984, p. 70). The author 


\title{
Dialogic Lessons and Triadic Relationship Among Pupils, Learning Topic, and Teacher
}

Kiyotaka Miyazaki

and heroes do not share the event. They do not have an equal right to know the event. How would that relation have changed if Dostoevsky had written the same material?

\begin{abstract}
He would not have retained for himself any essential authorial "surplus" (essential, that is, from the point of view of the desired truth). He would have arranged a face-to-face confrontation between the truth of the noblewoman and the truth of the coachman, and he would have forced them to come into dialogic contact (although not necessarily in direct compositionally expressed dialogues, of course), and he would himself have assumed, in relation to them, a dialogic position with equal rights. The entire work would have been constructed by him as a great dialogue, but one where the author acts as organizer and participant in the dialogue without retaining for himself the final word (Bakhtin, 1984, p. 72; emphasis added).
\end{abstract}

A dialogic author presents all the information she/he has to the heroes, thereby abandoning her/his authorial surplus. This information involves information not only about the heroes but also their worlds and worlds the heroes cannot see. By sharing all information, the author loses the status of knowing best about the heroes. Thus, the dialogic author cannot possibly anticipate what heroes do or think better than any others, including the heroes themselves. Something new can always occur for the author, as for the heroes. Bakhtin called this unfinalizability. In summary, the dialogic author exists in relation to the heroes and the world of the novel, in which both the heroes and the author exist. The dialogic author shares with the heroes the world of the novel, providing a different meaning than theirs. The dialogic author acts simultaneously as the organizer and participant of the dialogue.

Bakhtin described how the dialogic author's two roles are performed more specifically. Regarding the organizer, the dialogic author presents all information to the heroes, as mentioned before. Other means such as "questioning, provoking, answering, agreeing, objecting" (Bakhtin, 1984, appendix 2, p. 285) are also used to organize the dialogue. In the case of Dostoevsky, Bakhtin particularly focused on provoking. According to Bakhtin, Dostoevsky employed the adventure plot "combined with the posing of profound and acute problems $\cdots$. It places a person in extraordinary positions that expose and provoke him, it connects him and makes him collide with other people under unusual and unexpected conditions" (Bakhtin, 1984, p.105). Posing unexpected problems to heroes is an important part of the author's work when generating the dialogue. The dialogic author is not a moderator or facilitator just sitting aside from the discussing heroes, assembling their points of view, and "completely denying his own point of view" (Bakhtin, 1984, p. 105). Regarding the author as a participant, Bakhtin emphasized her/his ability to hear voices. He stated that Dostoevsky had "an extraordinary gift for hearing the dialogue of his epoch, or, more precisely, for hearing his epoch as a great dialogue, for detecting in it not only individual voices, their dialogic interaction" (Bakhtin, 1984, p. 90, italic original). Thus, Dostoevsky could hear not only dominant voices, but also weak and not yet fully emergent ideas of heroes.

\section{Developmental Psychology}

In the 1970s, developmental psychology began focusing on the role of social relationships in children's cognitive development. A study on secondary intersubjectivity by Trevarthen and Hubley (1978) showed that at approximately nine months of age, infants begin to integrate object awareness and person awareness, which until then had functioned separately, and live in secondary intersubjectivity, or personobject-person awareness. Many studies have investigated secondary intersubjectivity's role in children's development of, for example, language (Moore \& Dunham, 1995). The research tradition of Trevarthen analyzes the triadic relationship among an infant, the world, and a parent, which is comparable to the triadic relationship among pupils, their learning object and a teacher; however, classroom lessons do not appear to have been focused on in this research tradition. 


\section{Dialogic Lessons and Triadic Relationship Among Pupils, Learning Topic, and Teacher}

Kiyotaka Miyazaki

Another research tradition started in the same period is by Perret-Clermont and her colleagues. Based on the Piagetian research tradition, she argued that cognitive and social processes scaffold each other (Perret-Clermont, 2015). In Perret-Clermont (1980), she explicitly referred to the triadic relationship. She argued that knowledge should be seen as "a relationship of interdependence between the knowing subject and other knowing subjects, as well as between these and the object of knowledge" (ibid. p. 23).

However, the knowing subjects in this triadic relationship appear to be understood as children in that the relation between two knowing subjects appears to be understood as the relation between children. Their typical experimental situation was designed to observe how children from different developmental stages interact in a task on conservation of quantity. She did not refer to the teacher explicitly in these works.

The final researcher I mention in this section is Tomasello, who analyzed the development of the triadic relationship as the development of shared intentionality at the ontogenetic (Tomasello, Carpenter, Call, Behne, \& Moll, 2005) and on the human history (Tomasello, 2014) level. A triadic relationship emerges during the stage of joint intentionality, in which people have perspectivity and can experience the world as their own and from another person's social perspective; this is the first edge of the wedge between subjective and objective (Tomasello, 2014). Although Tomasello's research addressed learning and cognition in social relations, he focused on individual intentionality, and "the relations with others" are problematized only as perspectivity. Tomasello did not focus on the teacher's role explicitly either.

In summary, the concept of the triadic relationship plays a critical role in these studies of developmental psychology; however, they do not focus explicitly on the triadic relationship among pupils, their learning material and the teacher.

\section{Dialogic Pedagogy}

To demonstrate the result of analysis in advance, all theories examined in this section assume the triadic relations between pupils, their learning material and the teacher, at least implicitly. The theories also insist that, in some form, the teacher is the learner. Notably, there are varied options regarding what these theories assume about a teacher's learning; thus, this analysis focuses specifically on how these theories characterize the teacher's learning of the learning topic.

Researchers focusing on the rules for dialogue

Some researchers have argued that setting rules for conversation is the most important factor in making lessons dialogic. Examples include Mercer (Mercer, 1995; Mercer \& Littleton, 2007), Wegerif (2007), and Burbules $(1993,2006)$. Mercer characterized a lesson as an intermental development zone (IDZ), based on and elaborating Vygotsky's zone of proximal development (1978). In this zone, "a learner can stay attuned to each other's changing states of knowledge and understanding over the course of an educational activity"; to construct this zone, a teacher and a pupil "must use talk and joint activity to create and negotiate a shared communicative space, the IDZ" (Mercer \& Littleton, 2007, p.21).

Mercer distinguished three types of conversation in the classroom lessons: disputational, cumulative, and exploratory. Exploratory talk, in which pupils engage with each other critically and constructively, is dialogic. However, pupils do not necessarily learn this means of talking spontaneously. The teacher is responsible for guiding and modeling language use, as well as setting ground rules for the conversation to be dialogic. In Mercer's view, then, dialogic conversation in the classroom lessons follows certain rules, for example, sharing ideas, providing reasons, questioning ideas and so on. 


\section{Dialogic Lessons and Triadic Relationship Among Pupils, Learning Topic, and Teacher}

Kiyotaka Miyazaki

Wegerif, in collaboration with Mercer, added the concept of reflective dialogue as a dialogic talk, which elaborate exploratory talk "to include the non-verbal dimension and the reflection and creativity that was missing from the original concept" (2007, p. 190). Although Wegerif focused on interactive computer learning, he emphasized on setting ground rule for making lessons dialogic.

How did these researchers determine a triadic relationship? The cue to thinking about this topic is how they characterized the teacher. Mercer (2007) argued that the teacher should be the facilitator and colearner, instead of the instructor and transmitter. Furthermore, he argued that pupils and a teacher should share the tasks or problems, or the learning topics, as referred to in this paper, to maintain intersubjectivity (Mercer, 2007, p. 25). Mercer implicitly assumed that a triadic relationship exists among pupils, tasks and problems or, more generally, the learning material and a teacher.

Mercer did not discuss what and how a teacher learns in tasks or problems. For Mercer, the central characteristic of a dialogic lesson is the existence of certain rules of conversation and not how pupils and a teacher understand the learning topics. Thus, we cannot expect Mercer to discuss the teacher's learning of the learning topic, although he used the term co-learner to describe the role of a teacher. We also cannot expect him to discuss about the teacher's learning from pupils, because according to him, pupils are novices and a teacher is an expert.

Burbules is another researcher who considers the dialogue a conversation that follows certain rules, including rules of participation, commitment, reciprocity, and so on. He argued that both pupils and a teacher can learn from each other (Burbules, 1993); however, he did not clarify what and how a teacher learns. Burbules merely argued that a questioner can be questioned in turn, and this is a condition "that helps to create and maintain a dialogical relation of mutual respect and trust" (Burbules, 1993, p. 89). As Burbules did not make the third term clear, I cannot assert that he assumed a triadic relationship among pupils, the learning material and a teacher.

\section{Community of Learners}

Rogoff developed the concept of communities of learners and argued that "learning occurs as people participate in shared endeavors with others, with all playing active but often asymmetrical roles in sociocultural activity" (1994, p. 213). Regarding the participants in the community of learners, she said that "both mature members of the community and less mature members are conceived as active; no role has all the responsibility for knowing or directing" (Rogoff, 1994, p. 213). In these arguments, she stated that mature members such as teachers and less mature members like pupils share endeavors, thereby demonstrating an understanding of the triadic relationship among a teacher, the learning topic, and pupils.

For Rogoff, how is the teacher positioned? The teacher is responsible for guiding and supporting children's changing participation in their shared endeavors (Rogoff, Turkanis, \& Bartlet, 2001). The teacher is also considered an active learner. Unlike Mercer and others, Rogoff clearly emphasized that a teacher learns from pupils. In Rogoff et al. (2001), a record of their practice of the community of learners, a teacher who participated in the project, said, "In a learning community, a teacher learns a great deal from students about how to chart the direction of the curriculum" (Rogoff et al., 2001, p. 133). According to Rogoff, a teacher learns how to teach the content material or the teaching method from pupils.

Some comments are in order on the other researcher, Ann Brown, who adopts the view of community of learners. In a community of learners, both pupils and a teacher own certain forms of expertise and work collaboratively to discover knowledge (Brown \& Campione, 1994). Consequently, she assumed a triadic relationship among pupils, knowledge and a teacher. Regarding a teacher's relation with learning 


\section{Dialogic Lessons and Triadic Relationship Among Pupils, Learning Topic, and Teacher}

Kiyotaka Miyazaki

material, she pointed out the possibility that a teacher's ignorance has possible implications on pupils' learning:

Consider the case of the teacher who does not know the answer, or one who may share the students' puzzlement or misconception. In this case, the teacher is first required to recognize this fact (which the teacher might not be able to do), and, after admitting puzzlement or confusion, find ways to remedy it, for example by seeking help (Brown \& Campione, 1994, p. 262).

Brown appeared to have understood the importance of a teacher's discovery of certain difficulties in the learning material and the resulting implication on pupils' learning. Notably, the discovered difficulties are not only of pupils but of a teacher her/himself. Brown understood the importance of a teacher's learning of pupils' learning material and the discovery of her/his ignorance in them for pupils' learning.

Similar to the researchers of community of learners such as Rogoff and Brown, Wells' view (1999, 2000) characterized a teacher as a co-inquirer into the learning topic with the pupils. Starting from Vygotsky's (1978) zone of proximal development, Wells expanded the idea to include teachers receiving "help and guidance from the questions and suggestions of learners" (Wells, 1999, p. 312). Compared with other researchers of community of learners, Wells focused on teacher more explicitly and described in more detail what a teacher as a co-inquirer learns about the topic and how she/he works in the classroom.

Wells argued that the teacher has two roles: co-inquirer and organizer of lessons. As a co-inquirer, a teacher explores with pupils the topics she/he has chosen to investigate (Wells, 2000, p. 65). A teacher does not necessarily understand everything about the topics, and it is important for her/him to say honestly, "I don't know. How could we find out?" This response creates "an ethos of collaborative inquiry in the classroom and will make the teacher an excellent model for pupils" (Wells, 2000, p. 65). The other role as leader and organizer of the community's activities has two distinct levels. One is the macro level, in which the teacher is "the chief initiator and is responsible, among other things, for selecting the themes for curricular units and the activities through which they are to be addressed" (Wells, 1999, p. 243). More specifically, the teacher presents pupils challenging activities, including thought-provoking questions (Wells, 1999, p. 206). The other level is the micro level, in which the teacher responds to pupils' activities in the classroom, including listening to them. To summarize Wells' view, he assumed a triadic relationship among pupils, the topics, and a teacher explicitly. A teacher is simultaneously the organizer and the coinquirer of lessons. Like Brown, he suggested that a teacher's learning of learning of the learning material, in particular the discovery and admittance of her/his ignorance in it, was critical to pupils' learning.

\section{Freire's “cultural-dialogic" pedagogy}

Freire developed his dialogic pedagogy from his interest in the liberation of the oppressed. Compared with the researchers discussed thus far, his theory more clearly described a teacher's possible learning of the learning topics from pupils and equal rights vis-à-vis the truth of the learning topics for both a teacher and pupils. Freire understood the importance of a triadic relationship among pupils, the learning topics, and a teacher. He states the following:

[A]ny educational practice always implies the existence of (1) a subject or agent (a person who instructs and teaches); (2) the person who learns, but by learning who teaches; and (3) the object to be imparted and taught-the object to be re-cognized and cognized—-that is, the content (Freire, 1994, p. 93). 


\section{Dialogic Lessons and Triadic Relationship Among Pupils, Learning Topic, and Teacher}

Kiyotaka Miyazaki

Regarding the relationship between pupils' learning material and a teacher and what a teacher is supposed to learn, he wrote, "Here, in teaching, the teacher re-cognizes the object already cognized, already known. In other words, she or he remakes her or his cognizance in the cognizance of the educands" (Freire, 1994, P. 68).

A teacher as an adult already learns the learning topic and already has some "cognizance" about the topics. However, she/he "remakes" her/his cognizance anew when engaging with pupils. This implies that the teacher's remade cognizance is possibly influenced by pupils' cognizance of the learning topics, that is, the teacher learns about the learning topic from pupils.

What according to Freire could a teacher learn about the topics from pupils? Answering this question clearly is difficult. Although Freire (1994) wrote much about his experience with peasants in Brazil, I could not determine a clear illustration of his remaking his cognizance of something. Regarding this topic, Matusov (2009) argued that, for Freire, a teacher's learning from pupils is accidental. Matusov characterized Freire's dialogic pedagogy as "cultural-dialogic."

Freire's version of dialogic pedagogy can be defined as cultural-dialogic because he believed that knowledge emerges dialogically but exists in culture (e.g., artifacts and historically established consensuses) (Matusov, 2009, p. 92).

According to Freire, the phrase "knowledge exists in culture" implies that knowledge does not continue to be created anew in the dialogue but exists as finished in the culture, independent of the participants in the dialogue. This view applies particularly to the scientific concepts, shown as follows:

By discussing dialogue every day with students, I am not changing every day my understanding of dialogue. We arrive at the level of some certainty, some scientific certainty of some objects, which we can count on. What dialogue educators know, nevertheless, is that science has historicity (Freire \& Shor, 1987, pp. 101-102).

Although science itself has historicity and is constantly changing, as a learning topic in education, it has "some certainty" and is considered fixed outside of the classroom. This is what Matusov meant when he wrote about Freire that knowledge exists in the culture. For Freire, knowledge is fixed outside of the classroom, and pupils and a teacher should make that fixed knowledge their learning's endpoint. Therefore, the teacher would not be able to make (or remake) knowledge anew in each lesson by learning from pupils or other sources. In summary, Freire's teacher is one who remakes her/his cognizance she/he once made in learning pupils' learning material. He supposed that a teacher could not discover something really new in learning with pupils in the classroom.

\section{Matusov's authorial learning}

The central concept of Matusov's $(2009,2011)$ dialogic pedagogy is authorial learning. People have authorship, in which they can contribute uniquely and creatively to the community of which they are members. Authorship develops through authorial learning, which is made possible in dialogic education. In Matusov's view, the teacher's learning of the learning topic is vital for the teacher to help pupils' authorial learning. He also argued that the teacher learns about the learning topic from pupils.

Matusov's view of the triadic relationship among pupils, pupils' learning material and the teacher is shown clearly in his concept of the "epistemological non-authority of teacher and students" (2009, p. 86, 


\section{Dialogic Lessons and Triadic Relationship Among Pupils, Learning Topic, and Teacher}

Kiyotaka Miyazaki

italics original), in which the teacher and pupils are thought to have equal rights vis-à-vis the truthfulness of the learning topic.

Consequently, both teacher and pupils can surprise each other during dialogic lessons. That is, something unexpected can happen in the dialogic classroom, unexpected not only by pupils, but also by the teacher. Thus, the classroom lesson in dialogic education is not a one-way path to the endpoint set by the teacher before the lesson, but a journey "into a curricular land"- -a historically emerging discursive space on the subject matter (in a broad sense) (Matusov, 2009, p. 86).

How does Matusov think about the relationship between the teacher and pupils' learning material? According to Matusov, the teacher promotes and supports pupils' authorship. Through dialogic provocation, the teacher engages pupils "in some inquiry through provoking responses that students are asked to justify and test against alternative responses" (Matusov, 2011, p. 37) to promote the development of pupils' responsive authorship and support their self-generated authorship. The teacher's dialogic provocation, such as "mapping students' ideas, providing alternatives, promoting the testing of ideas, and so on" (Matusov, 2011, p. 39) cannot guarantee success. Instead, success depends on whether the teacher can recognize and use the teaching-learning moments emerging during the lesson. This relates strongly to the teacher's learning of the learning topic. Only if the teacher challenges and aims to understand the learning topic, can she/he recognize and use the emerging teaching-learning moment in the interaction with pupils to help pupils learn. Matusov wrote:

This is possible only when the teacher him or herself is an active author of the culture..., which means that the teacher enthusiastically and seriously works on diverse curricular subjects as an active learner, scholar, and practitioner and "thinks aloud" with his or her students during the lesson (Matusov, 2011, p. 39).

Matusov emphasized the necessity for a teacher to learn pupils' learning material. It is authentic in that the teacher can discover something new in the material that she/he must have once learned and thought she/he understood, triggered by pupils' responses. Matusov called this phenomenon the collapse of teacher's knowledge. Matusov wrote as follows.

This role of the teacher as an epistemological learner is possible because knowledge has a communal nature and collapses when the community does not support it. The teacher's knowledge often collapses in the classroom due to the students' unfamiliarity with and untestability of the knowledge (yet) (Matusov, 2011, p. 39).

Why does unfamiliarity with and untestability of pupils' knowledge cause the teacher's knowledge to collapse? After all, once the teacher understands some knowledge, she/he would maintain that understanding even when engaging with pupils unfamiliar with that knowledge. To examine this topic, I draw on Matusov's (2009) case, in which the teacher engaged with pupils who became uncertain whether $2+2$ could be represented by the summation of a pair of two lines. Matusov argued that the teacher "has to suspend his or her epistemological certainty about this unconditional representation of integer numbers with lines until this certainty emerges in the students or it completely collapses in the teacher as well" (Matusov, 2009, p. 89). That is, when the teacher encounters pupils' uncertainty or incomprehensibility of the learning topic, she/he can doubt her/his certainty of knowledge of the learning topic and start thinking that the previous understanding of the learning topic was inadequate. This stimulates the teacher's new learning, which develops new understanding that pupils' uncertainty, or even misunderstanding, is possibly correct. 


\section{Dialogic Lessons and Triadic Relationship Among Pupils, Learning Topic, and Teacher}

Kiyotaka Miyazaki

In summary, Matusov assumed the triadic relationship in which pupils and a teacher can have equal rights vis-à-vis the truthfulness of pupils' learning material. A teacher can learn something new for her/himself in pupils' learning material when pupils' apparently peculiar responses are encountered. Matusov differed from Freire because Matusov acknowledged that a teacher can discover something really new in the lesson.

To sum up the discussion of the triadic relationship thus far, Bakhtin's view of his dialogic author was particularly relevant to the subject of this paper. Bakhtin assumed a triadic relationship existed among the author, the world of the novel, and the heroes in the dialogic, or polyphonic novel. Dialogic authors and heroes have equal rights vis-à-vis the truthfulness of the world of the novel. Dialogic authors have two roles: organizer and participant of the dialogue. Although the triadic relationship has been investigated in developmental psychology since the 1970s, I posit that the teacher's role has not been a specific focus of these studies. Regarding the studies of dialogic pedagogy, most researchers assumed the triadic relationship among pupils, pupils' learning material, and a teacher. Although many researchers considered the possibility of the teacher learning from pupils, not all researchers thought that the teacher can learn about something new in pupils' learning material from pupils. Some researchers, such as Brown and Wells, argued regarding the implication of teacher's ignorance on pupils' learning. Freire argued that a teacher can have an equal right with pupils vis-à-vis the truthfulness of pupils' learning material but did not think that the teacher could discover something new. Matusov claimed that a teacher could learn something really new in pupils' learning material when, in encountering with pupils' apparently peculiar responses, she/he experiences her/his knowledge collapse.

\section{Thoughts and Classroom Lessons of Saitou Pedagogy}

\section{Saitou's Thoughts on the Triadic Relationship}

This section analyzes Saitou pedagogy's view of the triadic relationship among pupils, pupils' learning material, and a teacher, particularly on the relation between pupils' learning material and the teacher. First, Saitou's writings are analyzed. Regarding the triadic relationship, Saitou wrote:

It should be, in the classroom lesson, that contradiction, opposition, clash and conflict break out between the teaching material, the teacher, and the children, and both the teacher and the children discover and create something new, and move to the new dimension by overcoming these states ${ }^{1}$ (Saitou, 1970a, p. 385.).

Teaching material is the technical term commonly used in Japanese education to describe the pupils' learning topic. Terms such as contradiction and overcoming have a Hegelian flavor, although Saitou referred to neither Hegel nor Marx, at least explicitly. Saitou's use of these terms might be from their "circulation in the air" because Marxism was highly popular in Japan in the 1950s and 1960s. Saitou asserted that both pupils and a teacher make their view anew by presenting their views on the teaching material, or the learning topic. In other instances, Saitou used the word correspond for this situation.

The teacher and the children, the teacher and the teaching material, the child and the child, the children and the teaching material. All these pairs should correspond, and resonate. A climax should come, explode and something new should be born as a consequence. The teacher's thought and the children's thought, the child's thought and the child's thought. These pairs should resonate so

\footnotetext{
${ }^{1}$ The current author translated all the Japanese texts used in this paper into English
} 


\section{Dialogic Lessons and Triadic Relationship Among Pupils, Learning Topic, and Teacher}

Kiyotaka Miyazaki

that new views emerge, and the new views return to the teacher and each child, making them bigger and richer (Saitou, 1970a, pp. 368-369).

In one dictionary, the meaning of correspond is "match or agree" (Pearsall \& Hanks, 2005). For Saitou, however, the term's meaning is completely different.

Corresponding necessarily produces something new. So, corresponding can mean confronting. Resonating and confronting draw strength from each other, producing in each other something different and new (Saitou, 1970a, p. 368).

As these quotations show, the triadic relationship for Saitou is the relation between two relations: the relation between pupils and pupils' learning material, or how pupils learn and understand the learning material, and the relation between pupils' learning material and the teacher, or how the teacher learns and understands pupils' learning material. For Saitou, the classroom lesson can be a place where the pupils and the teacher discover something new in the pupils' learning material. Their views on pupils' learning material sometimes contradict, oppose, and clash and some other new will be produced.

It should be noted that contradiction, opposition and clash in the above quotation do not necessarily mean a direct confrontation between pupils' views and the teacher's view about pupils' learning material in the classroom. Although such cases can actually occur, the majority are the cases such as when the teacher expects stereotyped views regarding the learning material from pupils; thus, she/he looks for new ideas in the learning material to stimulate pupils to think again their views. Or there are cases such as when pupils present, intentionally or not, new ideas that oppose and overthrow the teacher's old idea regarding the learning material. Some of these cases are presented later in this section.

\section{Teacher Who Learns Pupils' Learning Material}

Saitou pedagogy asserts that the teacher can learn the pupils' learning material authentically and the quality of learning is the important moment to make the lesson dialogic:

First of all, a teacher should wholeheartedly encounter and confront the teaching material in all its respects as one person. Understanding the material conceptually to make them explainable to others is not enough. The teacher should interact wholeheartedly with the teaching material, analyze it, have questions about it, ask her/himself, discover something, and create something-as one person. Through these endeavors, the teacher should accumulate new thinking, new logic, and new development. (Saitou, 1964, pp. 89-90)

For Saitou, notably, the teacher should learn the learning topic not as the one teaching it later, but as one person same as pupils. That is, the teacher's learning of the learning topic should not be only to learn, for example, what errors pupils tend to make or how to teach the teaching material effectively. It should not be merely to increase knowledge either. Teachers should generate questions, make new discoveries, and understand the material anew even for the learning materials for children which are apparently easy for and feel already understood by the teacher as an adult. Saitou named such teacher's learning of pupils' learning material as Kyouzai-Kaishaku, or interpreting teaching material.

Such learning can be characterized by Schulman's (1986) two categories of teachers' knowledge: subject matter content knowledge, the knowledge of the content of the subject matter, and pedagogical content knowledge, how to teach the subject matter content to the learners. Schulman argued that pedagogical content knowledge is unique and important for teachers. By contrast, Saitou thought learning subject matter content knowledge was vital for teachers. However, increasing the knowledge of pupils' 


\section{Dialogic Lessons and Triadic Relationship Among Pupils, Learning Topic, and Teacher}

Kiyotaka Miyazaki

learning material is not enough for Saitou. What the teacher should and can do is discover new questions and something new in pupils' learning material that is apparently easy for the teacher as an adult.

This view of the teacher's learning is not monopolized by Kihaku Saitou. Other practitioners not under the direct influence of Saitou have had similar views. This shows that Saitou's view was not an ideational concept produced from some theories but was based on the classroom practices in Japan. Although it was Saitou who talked about it most explicitly, some practitioners also wrote about it. For example, Harutoshi Ushiyama, who for 40 years had been a teacher and principal of elementary and secondary schools and who mentored many teachers in Nagano prefecture, stated the case as follows:

What is critical here [preparing the learning material] though, is that the teacher should be the one who feels the material bodily and has direct experience with and exploration about the material. Most important is exploration of the material. What is more important is to record in detail what occurs in the teacher's (bodily) self when the teacher feels the material-what surprises her or him, what she/he is keenly aware, and what she/he starts thinking (Ushiyama, 2013, pp. 151-152).

Ushiyama emphasized the importance for teachers to feel pupils' material bodily and have direct experience with the material in their learning. People sometimes tend to believe that they understand a topic but actually only know the topic's linguistic definition. To understand deeply, they must connect their linguistic understanding with their direct, bodily experiences with the topic. The teacher should do this in her/his learning of pupils' learning material. This is what Ushiyama argued. Saitou wrote that understanding the material conceptually to make it explainable to others is insufficient in the previous quotation (Saitou, 1964, pp. 89-90). Ushiyama's argument supplements this Saitou's view. During teachers' learning of subject matter content knowledge, they should feel, directly experience, and explore the material-actions which are also expected to occur in pupils. In this sense, teacher's learning does not differ from that of pupils.

Teacher's learning of pupils' learning material, or Kyouzai-Kaishaku, is first carried out by the teacher in the preparation phase of the lesson. Although the teacher imagines what and how pupils think of their learning topic in her/his learning, pupils exist in the relationship only indirectly. However, KyouzaiKaishaku can be carried out in the middle of the classroom lesson. In these cases, the teacher can learn something new in the learning material from pupils in the interaction with them of the lesson.

The classroom lesson is not a practice in which the teacher teaches her/his fixed knowledge or the conceptual knowledge one-sidedly to pupils. It is a practice during which both the teacher and children transform incorrect or narrow and low-quality views they possessed so far about the learning material to new ones and transform their old ways of being to new ones by presenting and examining each other their views on which they stake themselves (Saitou, 1975/1995, p. 7).

Saitou argued that not only pupils but also the teacher can make new their old and wrong understandings in the exchange of each other's views between pupils and the teacher. Notably, as shown before, the exchange of views does not necessarily take the form of direct confrontation between pupils' views and the teacher's view in the lesson. More important is the case in which pupils present, intentionally or not, new ideas that oppose and overthrow the teacher's old ideas on the learning material. When the teacher notices the possibility of new ideas in pupils' utterances, the teacher can learn something new regarding pupils' learning material from pupils. In the section "Discovering Unknown Questions in Pupils", I explain how this process occurs. 


\section{Dialogic Lessons and Triadic Relationship Among Pupils, Learning Topic, and Teacher}

Kiyotaka Miyazaki

\section{Discovering Unknown Questions in the Preparation of the Lesson}

Thus far, I have presented Saitou's thought expressed in his writings. Although these thoughts are based on Saitou and other teachers' practices, they show what Satiou thought what teachers should do to create the ideal lessons in practice. How will these thoughts be materialized in the real lessons? In the following sections, some of the lessons by teachers of Saitou pedagogy are presented and analyzed.

Based on analysis of Saitou's view and the classroom lessons developed under his influence, Miyazaki $(2005,2009,2014)$ argued that the important part of teacher's learning, as the exploration of the learning topic to be learned, is to discover the unknown question, the existence of or the answer to which the teacher does not know before the lesson. Of course, learning topics, in elementary schools for example, seem easy for adult teachers; there seems to be no possibility of the teacher encountering something unknown. Nevertheless, the teacher should and can discover authentic questions even regarding apparently easy learning topics when she/he confronts those topics wholeheartedly. Questions discovered during such learning can also be interesting for pupils and stimulate them to generate additional new questions.

A lesson example from social studies

One typical example is a social studies lesson exploring "What is a shop?" by Katsuhiko Sakuma (Sakuma,1992; Miyazaki, 2014). As a researcher of social studies education, Sakuma learned Saitou's view and developed a classroom method he called fieldwork lesson, in which pupils learn about society not from books but from exploring questions in the field. To start this lesson, teachers should conduct fieldwork to discover an unknown question. Such questions are the first step of the lesson.

An example of this type of lesson is as follows. He has conducted this lesson using this topic in many classes, and the one introduced next was a lesson for a fifth-grade class of 31 pupils conducted in June, 2002 and observed by the author.

At first, pupils were shown five photos and asked if each photo was a shop, a grocery store, a barbershop, a launderette, a vending machine and a peddler. In the observed class, 30 answered yes for a grocery, 16 answered yes for a barbershop, five answered yes for a launderette, one answered yes for a vending machine and no one answered yes for a peddler. Next, pupils discussed for each picture if it was a shop. What follows is the record showing the discussion about a vending machine:

Teacher: Next. The vending machine. Who thinks that the vending machine is a shop? Five of you.

Pupil: It is a shop because you can buy goods by putting coins in it.

They have already learned that they had to pay money to buy service so that the barber is a shop when they discussed about the barbershop.

Pupil: Because there is an owner of the vending machine.

Teacher: Who thinks it is a shop?

The number of pupils who said yes increased to ten, and the number of pupils saying no reduced to only a few.

Teacher: Why isn't it a shop?

Pupil: It doesn't work when it fails, or after the company's closing time. 


\section{Dialogic Lessons and Triadic Relationship Among Pupils, Learning Topic, and Teacher}

Kiyotaka Miyazaki

Teacher: We cannot use shops sometimes even when there is a shop clerk.

Pupil: Yeah. Machines are more robust.

Pupil: (In the case of) sell out (you cannot use the vending machine).

Teacher: You can experience something being sold even in a grocery. More so than in the vending machine.

The teacher did not conclude the discussion and moved to the next question regarding the peddler. After discussing about all five photos, Sakuma listed up to eight features of the shop that appeared in the lesson and checked if each feature was applicable to each item. All eight features were applicable only to a grocery and a barber. Next, Sakuma told a short history of a shop to the pupils. He did not conclude if these phots except for a grocery and a barber were shop or not. At the end of the lesson, Sakuma asked pupils to ask people around them if these phots except for a grocery and a barber were shop or not.

This lesson was intended to be a demonstration of a fieldwork lesson for teachers of the school and the allocated time was only 100 minutes; thus, the lesson ended before pupils' fieldwork started. Nevertheless, the pupils must have learned a variety of knowledge in the lesson and one of piece of knowledge must be that a seemingly simple problem, in this case, if a vending machine is a shop, cannot be answered easily and can result in many topics for discussion. One third grader from a class Sakuma taught on a different occasion wrote the following comment after the class:

Although I had thought that it was not a shop if there was no salesclerk, now I am not sure. Although I did not think that a launderette was a shop though it was in a house and we paid a money for it, now I am not certain. (Sakuma, 1992, pp. 37-38)

This comment showed that the third grader had had some understanding and felt that she had known what a shop was before the lesson. The lesson experience had unfinalized her understanding and new questions had been generated.

How did Sakuma prepare for the lesson? I conducted an interview with Sakuma to know his preparation process for the lesson (Miyazaki, 2009). Sakuma told me that it started with the vending machine because he heard someone ask if a vending machine could be defined as a shop in some occasion. Sakuma then asked this question to a variety of people, such as owners of a nearby shop, and a salesperson of vending machines, and their answers differed. He also visited the Chamber of Commerce and Industry of his city and the Ministry of Economy, Trade and Industry to obtain the answer but did not receive a clear answer. He also asked a jurist and learned that there was no explicit definition of shop in Japanese Commercial Law. Thus, Sakuma's fieldwork showed that the question regarding a vending machine had no definitive answer even academically, and the answer to this question depended on which aspect of a vending machine was the focus.

For the lesson, Sakuma added a launderette and a peddler as nontypical cases similar to a vending machine, a grocery as a typical shop, and a barber as an in-between case so that pupils could compare these different items to think about what is a shop.

The question "what is a shop" appears easy to answer at first. However, this question becomes suddenly difficult to answer when asked if a vending machine is a shop. As Sakuma knew from his fieldwork, there was no definitive legal answer. This question is a typical unknown question in the sense that it has no clear answer. This type of question can have different answers depending on the feature people focus on. The characteristics of this type of question make it attractive as a topic for the classroom lessons, 


\section{Dialogic Lessons and Triadic Relationship Among Pupils, Learning Topic, and Teacher}

Kiyotaka Miyazaki

stimulate pupils' interest, and bring out a variety of views for pupils to explore. In other words, this type of question could stimulate dialogic interaction among pupils.

\section{Discovering Unknown Questions in Pupils}

There is another type of unknown questions that the teacher can determine in pupils' utterances during lessons. The teacher's discovery of such questions occurs often when pupils' answers to the teacher's previous question seem wrong or irrelevant. In that case, possibly, a pupil has a question different from that of the teacher. The pupil's answer to the teacher's question might seem wrong or irrelevant, but the teacher's expected answer is not an answer to the pupil's actual question. This type of question is unknown to the teacher in the sense that the teacher did not know its existence before noticing it in pupils' utterance. Yukio Tsukamoto, who had worked as an elementary school teacher and is developing his pedagogy under Kihaku Saitou's influence, made this observation:

The child interprets the teacher's asked question, chooses one among many possible implied questions as her/his own, and answers it. Sometimes, the child choses a question that differs from the teacher's intended one. In that case, the child' answer is not likely to match the teacher's expected answer; the teacher thinks the answer is incorrect. However, if the child's answer can be traced back to the child's question which brought the answer, the teacher can become aware of a new view of the learning topic hidden in the child's incorrect answer (Tsukamoto, 2014, p. 25).

Notably, any question presupposes a horizon of the question (Gadamer, 1975). Gadamer wrote as follows:

To ask a question means to bring into the open [omitted]. The openness of a question is not boundless. It is limited by the horizon of the question. [omitted]lt becomes a question only when its fluid indeterminacy is concretized in a specific "this or that." [omitted]It implies the explicit establishing of presuppositions, in terms of which can be seen what still remains open (Gadamer, 1975 p. 357).

In summary, a horizon of the question is the presuppositions that the questioner takes for granted, defining the question's meaning. When two people seem to share the same question, their questions actually differ if their horizons for the questions differ. The expected answers are different for these two people even though two questions are apparently the same.

When the teacher asks a question, she/he unconsciously presupposes some horizon which, in turn, determines the expected answer. The pupil, however, does not necessarily have the same horizon as the teacher. In that case, the pupil seems to answer the teacher's question with its horizon but actually answers a different question with the pupil's horizon. Consequently, the pupil's answer might be wrong or irrelevant to the teacher's question, but not wrong nor irrelevant to her/his own question. The pupil's wrong or irrelevant answer can be a hint for the teacher to discover that the pupil has a different question with a different horizon from the teacher's own question. Because the pupil's question is unexpected and unknown to the teacher, the teacher can develop new understanding of the learning topic when the teacher discovers the pupil's question. In such cases, the pupil teaches the teacher something new about the learning topic. The teacher's discovery of the unknown question in the pupil provides the pupil with an opportunity to exercise her/his right equal to the teacher vis-à-vis the truth of the learning topic.

The pupil was also likely unaware that her/his question differed from the teacher's. The teacher's discovery of the pupil's question makes it possible for the pupil to become aware of her/his question, to share it with other pupils and the teacher, and to conduct collaborative exploration of the question with 


\section{Dialogic Lessons and Triadic Relationship Among Pupils, Learning Topic, and Teacher}

Kiyotaka Miyazaki

them. A teacher's discovery of an unknown question in a pupil's response can be a notable teaching moment that creates an opportunity for a dialogic lesson.

An example lesson for a literature class 1: Noting a new question in pupils' wrong answers

The example that follows is Tsukamoto's example in which the teacher discovers an unknown question in pupils' wrong answers. Unfortunately, the lesson did not unfold further from the question due to time limits. Nevertheless, this example, a lesson observed by the author on December 12, 2008, illustrates that new questions can be discovered in wrong answers. In a sixth-grade class, the learning topic was a pre-World War II poem titled "Haru" ("Spring"), written by Japanese poet Fuyue Anzai (1898-1965).

"Haru" ["Spring"]

Tefutefu ga ippiki Dattan kaikyou wo watatte itta.

[A butterfly has gone alone over the Dattan Strait]

The poem is difficult because the word Tefutefu(butterfly), written with four hiragana characters, or the Japanese phonogramic characters te-fu-te-fu, should be pronounced cho-u-cho-u. Today, however, younger people cannot pronounce and understand te-fu-te-fu as cho-u-cho- $u$ because notational rules have changed; thus, it should be written with four hiragana characters cho-u-cho-u. At the beginning of the lesson, the teacher asked,

Teacher: It is Ippiki. What do you think it is?

Ippiki means Ichi-Hiki or one-Hiki, in which Hiki is a counter used for many types of animals and bugs and, therefore, for a butterfly. In Japanese, different counters are used for different things, like wa for birds. Thus, Tsukamoto focused on the counter when questioning the meaning of te-fu-te-fu. Pupils' answers were divided into three types. Nine pupils correctly answered "butterfly," eight answered "fish," and seven answered "bird." When Tsukamoto asked why, the pupils who answered "butterfly" provided the following reasons.

Pupil: Tefu is repeated twice in tefu-tefu like cho-u is in cho-u-cho-u.

Pupil: The title is "Spring," when butterflies start flying.

Pupil: It is a butterfly because it is Ippiki. If it is a bird, it must be Ichi-wa.

Tsukamoto asked again what tefu-tefu meant, and "a butterfly" became the majority of the 19 responses, compared with three for "bird" and nine for "fish." Next, Tsukamoto asked for reasons why the pupils chose "fish."

Pupil: Because it has gone over the strait that a bird cannot go over.

Tsukamoto: Oh, it is a good point. Because it has gone over the strait. What is a strait?

Pupil: A border between nations.

Tsukamoto: That is a national border.

Pupil: A border between something?

Tsukamoto: So, the sound of the word makes you think that it is some type of border. A strait is a sea between two places, between an island and a continent or between an island and an island. For example, the Tsugaru Strait is between Honshu Island and Hokkaido Island. Mamiya Strait is between Sakhalin Island and the continent. As you are thinking about tefutefu, you are also thinking about the meaning of spring and strait as relating to tefutefu. 


\section{Dialogic Lessons and Triadic Relationship Among Pupils, Learning Topic, and Teacher}

Kiyotaka Miyazaki

Next, Tsukamoto asked the same question a third time and the result was surprising. The number of pupils who answered "butterfly" decreased to six, and those who answered "fish" became a majority of more than 20. The teacher later told me who observed this lesson, that he did not expect such answers and wondered what he should have done next. Having the pupils discuss this topic was one possibility. Instead, he provided the children with the correct answer because it was still early in the class and many topics remained in the poem that the class had to discuss. Thus, he told the class, "This is not a fish but a butterfly." But he did not stop there. He continued as follows:

Tsukamoto: The way you feel is great! Bird, okay. Fish, okay. But it cannot be a butterfly.

Although "bird" was simply wrong, Tsukamoto not only told pupils the correct answer, but also evaluated their answers highly. Why? When Tsukamoto asked pupils what tefutefu was, he meant, "what does the written 'te-fu-te-fu' mean?" "Fish" was clearly the wrong answer to this question. However, for pupils who answered "fish," tefutefu was something that has gone over a strait that a bird cannot go over, as one pupil had answered. In other words, the question "what is tefutefu?" meant, for the pupils, "what is the tefutefu that has gone over such challenging strait?"

Tsukamoto and the pupils who answered "fish" apparently shared the same question. However, they had different horizons; thus, their questions were different. Tsukamoto's horizon was that pupils must have been interested in how to pronounce the word 'te-fu-te-fu. ' He also presupposed that pupils would develop the imagination of the poem's world after they understood the word's correct meaning. With this horizon, the question "what tefutefu was" meant "what does the written 'te-fu-te-fu' mean?" for Tsukamoto and the correct answer was "a butterfly."

Pupils, at least some of them, had a different horizon. Their horizon was that some animal named 'tefutefu' had crossed over the harsh environment of the Dattan strait. Different from Tsukamoto's expectation, pupils had already imagined the poem's world. With this horizon, the question "what tefutefu was" meant "what is the tefutefu that has gone over such harsh strait?" for pupils, and the correct answer was "a fish." Although apparently the same as Tsukamoto's original question, it had a different horizon compared with the question from Tsukamoto.

Such questions discovered in pupils' seemingly wrong or irrelevant answers can be the starting point for further exploring the learning topic (Miyazaki, 2014). As previously mentioned, the discovered question was not discussed during this lesson due to a time constraint. Thus, whether the discovered question was important to pupils remained undetermined. Nevertheless, this interaction illustrates the importance of teachers' understanding pupil's answers not just as wrong or irrelevant, but as novel questions with different horizons.

Treating an answer simply as wrong or irrelevant exercises the teacher's exclusive right vis-à-vis the truth of the learning topic. Trying to discover some new question in pupil's wrong or irrelevant answer is to learn something new about the learning material from the pupil. In doing so, the teacher recognizes the pupil's equal right vis-à-vis the truthfulness of the learning topic. In this sense, this episode is dialogic

An example lesson for a literature class 2: A pupil and a teacher learn from each other

The next example is a sixth-grade literature class, in which a teacher named Megumi Arakida requested pupils to explicitly produce questions about the material. The teacher previously worked in an elementary school whose principal was Tsukamoto, from whom she had learned a lot. The lesson was conducted in November 2013 and was recorded by the teacher (Arakida, 2013). 


\section{Dialogic Lessons and Triadic Relationship Among Pupils, Learning Topic, and Teacher}

Kiyotaka Miyazaki

In a question produced by one pupil, the teacher found out a new, possible question and presented it to the pupil. For the pupil, the question he originally produced seemed to be more meaningful; thus, he did not accept the teacher's proposal and pursued his question. For the teacher, the question she found out in the pupil was appeared to be new and not known before; thus, the pupil's question provided an opportunity for her to learn the learning material authentically.

The material was a fantasy writing called $A$ Fox's Window, by Naoko Awa. A hunter chased a little, white fox, wandered into a beautiful bellflower field, and met the little fox who turned to an employee of a dye-house. The little fox dyed, at first, his own fingers, with which he formed a window. The hunter looked in the window and saw the mother fox, which had been shot. He wanted to have a window himself and asked the little fox to dye his fingers. Looking in at the window made with his fingers, he saw a girl he once loved. He felt happy and gave the little fox his gun as a reward. On the way home, he formed the window again and looked in; he saw the house and the garden he loved and once lived in, heard his own and the dead sister's voices, but he did not see his mother's figure.

One boy, Masa, produced a question in a group discussion and wrote his question on his notebook: why did the girl appear in the window first. Masa wrote the answer to his own question: because both the girl and his family are valuable to him. For Masa, to ask why the girl appeared first was actually to ask whether the girl was more valuable than his family, to which his answer was that not the girl, not the family, but the both were valuable.

When the teacher heard Masa asking his question to the group, she said to Masa at once, "oh, you can ask such a question that the hunter wanted to see which one." She felt that there was something new in Masa's question for her. She was so excited thinking about how she would answer Masa's question as a learner. After the discussion was over, the teacher commented further on the notebook to Masa as follows.

Teacher: It is great to focus on which one appeared first, the girl or the family. Yes, both were valuable, but I think it significant that the family appeared in the window next to the girl, because the girl could have appeared repeatedly.

Here, the teacher discovered the possibility of a somewhat different question from Masa's original question and proposed it to him. For Masa, the question focused on which one, the girl or the family, was valuable. Masa's horizon was that two figures, the girl and the family, appeared in the window and the order of appearance was not important. The teacher, on the other hand, focused on the girl not appearing repeatedly. The teacher's horizon was that the order of appearance had notable implication. For the teacher, this implication suggested that although both were valuable and incomparable, they must still have had some qualitatively different values. The teacher had never thought of this idea before Masa's questioning; thus, she learned from him.

Masa wrote his response in a notebook.

Masa: I cannot choose which one the hunter wants to meet. It is the ultimate choice!

Although he did not change his view that both were valuable, he developed his own view from that both were valuable; thus, he could not choose one. In this sense, he learned something in the exchange with the teacher.

In this case, the teacher discovered a new possible question different from the pupil's original question in the pupil's utterance. The teacher did not notice the question and the horizon behind it before 


\section{Dialogic Lessons and Triadic Relationship Among Pupils, Learning Topic, and Teacher}

Kiyotaka Miyazaki

the pupil proposed his thought. The teacher learned a new view regarding the learning material from the pupil. On the other hand, the pupil was proposed a new possibility for his view, but did not accept that proposal, and chose his original question. Nevertheless, the pupil developed his view in his own way.

There was opposition between the teacher's proposed question based on her inference and the pupil's original question. The opposition was resolved but not in a manner such that one party won and the other lost. The teacher did not impose her thoughts on the pupil. The pupil, by contrast, did not merely reject but developed his own view.

This case showed that first, even if the teacher's inference regarding the pupil's possible answer is incorrect, the pupil's feedback can reflect the incorrectness, and second, that the teacher can learn something new regarding the learning material from the pupil by thinking about the pupil's possible question, and the pupil can learn something new from the teacher to develop her/his original idea if not accepted according to the teacher's view. Both sides learned from each other in the exchange. In this sense, both sides exercise their rights vis-à-vis the truthfulness of the learning material.

I summarize Saitou's pedagogical view as follows. The teacher is one component of the triadic relationship among pupils, learning topic, and the teacher. To make lessons dialogic, the teacher should learn the learning topic wholeheartedly as one person, even when the learning material appears easy for the teacher because the material is for young children. For Saitou, the purpose of teacher's learning of the learning material is not merely to accumulate new knowledge but rather discover something new in the material that she/he thinks she/he already understand. One product of such learning is the discovery of the unknown questions, to which she/he does not know the answer, or even of the question's existence prior to the lesson. The unknown question can be notable to the pupils, stimulating their learning and helping them discover their new questions about the learning topic. The teacher can learn new questions from pupils by finding out them in pupils' seemingly wrong, or irrelevant responses. The teacher can then share these questions and explore them collaboratively with pupils.

\section{Comparing Saitou Pedagogy and Theories of Dialogue and Dialogic Pedagogy}

\section{Bakhtin and Saitou Pedagogy}

In this final section, I compare Saitou pedagogy and theories of dialogue and dialogic pedagogy to elucidate Saitou pedagogy's characteristics. First, I discuss Bakhtin's view of dialogue.

Bakhtin's view of the dialogic author is helpful to analyze the dialogic characteristic of Saitou pedagogy. The dialogic author does not control and finalize heroes but unfinalizes them in the triadic relationship among the author, the world of the novel and heroes. Likewise, the teacher in Saitou pedagogy does not merely teach her/his thoughts to pupils one-sidedly but learns something new and discovers unknown questions from pupils in the lesson. The teacher is comparable to Bakhtin's dialogic author.

For Bakhtin, the triadic relationship becomes dialogic when the participants have equal rights visà-vis the truthfulness of the topic. A teacher of Saitou pedagogy exercises her/his equal rights with pupils vis-à-vis the truthfulness of learning material while the teacher learns pupils' learning material authentically to find out something new and unknown questions as pupils do, and the teacher not only teaches pupils about the learning material but also learns about the learning material from pupils.

Further, Bakhtin asserted that the dialogic author has two roles: the organizer of the dialogue and a participant of the dialogue. Teacher of Saitou pedagogy also plays two roles. As the organizer, she/he 


\section{Dialogic Lessons and Triadic Relationship Among Pupils, Learning Topic, and Teacher}

Kiyotaka Miyazaki

presents to pupils the unknown questions she/he discovered in the learning of the learning material to stimulate pupils to develop dialogic lessons. The teacher's presentation of the unknown question is comparable to the dialogic author's presentation of the adventure plot to the heroes, which Bakhtin pointed out as the device for Dostoevsky to develop the dialogic novels. As the participant, the teacher listens to pupils carefully to discover new, unknown questions in pupils.

Saitou pedagogy offers a new suggestion to develop Bakhtin's view of the dialogic author because it focuses on questioning, which Bakhtin did not discuss much. Although Bakhtin rarely referred to the issue of questioning, he did not ignore the topic completely. In his later writing, he wrote the following: Question and answer presuppose mutual outsidedness. If an answer does not give rise to a new question from itself, it falls out of the dialogue and enters systemic cognition, which is essentially impersonal (Bakhtin, 1986, p.168). Thus, I assert that it seems possible that the mutual outsidedness of question and answer Bakhtin wrote means the difference in the horizons of a questioner and an answerer (Gadamer, 1975). As aforementioned in "An example lesson for a literature class 1," pupils seemed to answer to the teacher's question but actually answered their questions, which had the apparently the same form but different horizons from the teacher's. In these cases, a new question is produced outside of the original question when the answerer answers the original one. Bakhtin might suppose that there could be a new question in an answer to the old question, which is the same as in Saitou pedagogy. This topic is worthwhile for further studies of Bakhtin.

\section{Theories of Dialogic Pedagogy and Saitou Pedagogy}

Brown and Wells: Lack of concern for the teacher's learning process

As the theories of triadic relationship in developmental psychology reviewed here did not treat the teacher as one term of their triads, they are not mentioned hereafter, and only the theories of dialogic pedagogy are discussed. The most important argument of Saitou pedagogy is that the teacher should and can learn pupils' learning material authentically to produce new understandings and new questions regarding it. The theories of dialogic pedagogy I have already reviewed can be classified into two types based on whether they focused on the teacher's authentic learning of pupils' learning material. Researchers focusing on the rules for dialogue such as Mercer and, among researchers of community of learners, Rogoff, did not focus on the teacher's authentic learning of pupils' learning material. Hereafter, researchers focusing on the teacher's authentic learning of pupils' learning material are compared.

Among the researchers of the first type, some have not provided satisfactory descriptions of how the teacher's authentic learning develops. Brown and her colleague mentioned teacher's ignorance, an important concern regarding teacher's authentic learning. They argued as follows: even teachers are free to reveal their ignorance of certain topics and to model methods used to overcome that ignorance ... (Brown \& Campione, 1994, p. 261). However, they pointed out that the teacher's ignorance is only overcome by consulting outside sources, and did not mention the possibility that the teacher becomes aware of her/his ignorance from pupils' responses and overcomes the ignorance by learning the new, possible questions from the pupils' responses.

Wells' arguments have many similarities to the views of the Japanese teachers. He argued that the teacher has two roles: organizer and co-inquirer. He stated the importance of the teacher's questions to organize the lesson. His thought-provoking question is apparently similar to the unknown question which I observed in Japanese practices. However, Wells did not explain how and in what sense his thoughtprovoking question actually provokes thought, much less how the teacher discovers such a question. 


\section{Dialogic Lessons and Triadic Relationship Among Pupils, Learning Topic, and Teacher}

Kiyotaka Miyazaki

Freire on the possibility of discovering something really new in the lesson

Among the aforementioned researchers, Freire and Matusov are examined in more detail in this and the next section. Freire argued that teachers can learn something from pupils' learning material from the pupils. However, he characterized this learning as the recognition of the object the teacher already cognized and did not suppose that the teacher can learn new things in the lesson. Scientific knowledge is in the culture with some certainty; thus, both pupils and the teacher cannot create something new about science in the classroom lesson. For Saitou pedagogy, however, pupils and the teacher can discover something new and significant even in science materials and, for the teacher, in the lesson preparation. In the lesson case of "what is a shop?" introduced before, for example, the teacher's fieldwork in the lesson preparation showed that there was no academic answer to this question.

As for pupils, they may have discovered something significant in the science lesson, but the teacher could not understand the implication of pupils' thoughts at first. One such instance occurred in Kazuyasu Azegami's sixth-grade math classroom. Azegami, now a professor of education at Shinshu University, was an elementary school teacher and had learned a lot from Harutoshi Ushiyama, as aforementioned. The class was held in May, $2001^{2}$.

The target problem was the division of a fraction by another fraction.

$$
\frac{3}{5} \div \frac{2}{3}
$$

Although the pupils knew that the answer could be obtained by multiplying the divided fraction by the inverse of the dividing fraction, they did not know why and began a discussion. At that time, Aki, a pupil, presented the following solution:

$$
\frac{3}{5} \div \frac{2}{3}=\frac{3 \times 6}{5 \times 6} \div \frac{2}{3}=\frac{18 \div 2}{30 \div 3}=\frac{9}{10}
$$

In the equation, 6 is the least common multiple of 2 and 3 , the numerator and denominator of the dividing fraction. Although the answer is correct, many pupils could not accept it because the method of solution was new and uncommon to them. Next, Aki developed the equation to show that he could demonstrate that the answer to the division by a fraction could be calculated by multiplying the divided fraction by the inverse of the dividing fraction.

$$
\frac{3 \times 6 \div 2}{5 \times 6 \div 3}=\frac{3 \times 3}{5 \times 2}
$$

After seeing Aki's demonstration and examining his solution for a different problem, by the end of class, many pupils approved of his thinking but thought his solution was too cumbersome. Notably, the teacher was surprised at first and could not understand Aki's solution. At the same time, the teacher believed there must be some validity to Aki's solution and did not deny Aki's idea. Instead, the teacher enjoyed Aki's idea and attempted to understand it. The teacher also showed the pupils the following equation to help them to understand Aki's thinking.

$$
\frac{3}{4} \div \frac{2}{5}=\frac{3 \times \square}{4 \times \square} \div \frac{2}{5}
$$

\footnotetext{
${ }^{2}$ K. Azegami, personal communication, November 29, 2016
} 


\section{Dialogic Lessons and Triadic Relationship Among Pupils, Learning Topic, and Teacher}

Kiyotaka Miyazaki

Still, the teacher felt there was something in Aki's idea beyond the teacher's understanding. Later, a mathematician found out about Aki's method and evaluated it highly by considering it notable (Ueno, 2001).

This instance is not exceptional. Hosoya, one of the developers of the science education method named Kyokuchi Houshiki or the polar method, argued that not always but sometimes, scientists have difficulty answering questions posed by pupils (Hosoya, 2001). Therefore, Freire's view of sharply distinguishing scientific practice by scientists from classroom learning seems off the mark. Classroom lessons are an arena in which authentic new questions and knowledge, notable even to professionals, can be created.

Matusov: Necessity to focus on questioning

Matusov's view is similar to Saitou pedagogy because he thought that the teacher could obtain a new understanding of the learning material when encountering pupils' seemingly wrong thoughts. Two views focus on the different aspects to explain this phenomenon. For Matusov, the teacher became uncertain about $2+2=4$ and started to examine a new possibility because the teacher was not supported by the pupils. The phenomenon is described as a collapse of communal knowledge. When new understanding emerges, it comes as "collective, communal knowledge of the classroom community" (Matusov, 2009, p.90). Matusov emphasized the communal nature of the phenomenon. This description is too coarse for Saitou pedagogy to understand the phenomenon. As aforementioned, Saitou pedagogy understands this phenomenon as the encounter between the pupils and the teacher who, although apparently shared the same question, has different questions with different horizons. It focuses on what occurs in each participant, namely, the pupil and the teacher in the encounter. For Saitou pedagogy, the teacher experiences not a collapse of communal knowledge but the awareness of new, unexpected questions in pupils when she/he encounters with pupils' wrong or irrelevant thoughts. The teacher also becomes aware of the horizon of her/his original question. Pupils, by contrast, accept the teacher's proposal and become aware of their implicit questions, or they do not accept the teacher's proposal, as shown in "An example lesson for a literature class 2." Even in these cases, the pupils make explicit their original questions, which are different from the teacher's proposal. In both cases, pupils can develop their questions further while collaborating with the teacher. In summary, Saitou pedagogy focuses on how each individual, each pupil and the teacher, with each unique question with each unique horizon, develops each one's question in their encounter, and this view contrasts with Matusov's view, which emphasizes the communal nature of knowledge.

When encountering Matusov's case, the teachers who learned Saitou pedagogy would think and behave in the following manner: The pupil becomes uncertain about $2+2=4$ not because he did not have the correct knowledge. He must have some experience in which 2 plus 2 is not equal to 4 . He must have thought about the question of $2+2$ with that experience as his horizon, which differs from the teacher's horizon. The teacher explores the pupil's horizon, and discovers, for example, that the pupil might have experienced the case described by Matusov, in which two friends and two other friends gather. Then, the teacher understands that the pupil's meaning of the question $2+2$ is different from his own with the horizon that the equation should represent a purely arithmetic relation abstracted from real-world experience. Thus, the teacher feeds back her/his understanding of the pupil's question to the pupil and can discuss with the pupil topics such as what the difference between their views is or if there are other answers and reasons for these answers other than theirs.

In summary, the teacher who learned Saitou pedagogy strives to discover questions they have not previously known in pupil's apparently wrong or irrelevant thoughts on the learning topic and share them 


\section{Dialogic Lessons and Triadic Relationship Among Pupils, Learning Topic, and Teacher}

Kiyotaka Miyazaki

with pupils. Sharing the new question initiates a new exploration of the learning topic by the pupils and the teacher. To be able to do so, the teacher should examine the learning topic deeply before and during the lessons. In Matusov's case, the teacher engaged in that process when he examined "a possibility that when two objects added to other two objects, they do not always (i.e., unconditionally) produce four objects" (Matusov, 2009, p. 89). And the teacher discovered an unknown question: What is the sum of two objects and another two objects when these objects interact with each other?

Matusov's view of the teacher as an epistemological learner is outstanding among theories of dialogic pedagogy because it clarifies that the teacher can learn from pupils' wrong or irrelevant thoughts. However, Matusov's analysis of the teacher's learning process remains an abstract argument in that knowledge is supported by the community. He does not understand that teacher's learning is a process of becoming aware of what questions pupils and the teacher have about the learning topic.

\section{Summary}

I examined how and in what form the triadic relationship among pupils, their learning material, and a teacher exists in dialogic lessons and how the teacher works in the triadic relationship to make lessons dialogic in this paper. The main target was the Japanese pedagogical thought called Saitou pedagogy and the classroom lessons produced in its tradition.

To examine Saitou pedagogy, theories of dialogue, developmental psychology, and dialogic pedagogy were reviewed regarding how these theories understand the triadic relationship. Bakhtin's view of the dialogic author was particularly useful to show the dialogic nature of the triadic relationship and the teacher's role in Saitou pedagogy. The dialogic author does not control and finalize heroes but unfinalizes them in the triadic relationship among the author, the world of the novel, and heroes. Likewise, the teacher from Saitou pedagogy does not merely teach her/his view to pupils one-sidedly. In the triadic relationship among pupils, their learning material, and a teacher, the teacher learns pupils' learning material authentically as pupils do to discover something new and unknown questions. The teacher also learns the possibilities of new questions regarding pupils' learning material from pupils. Teachers of Saitou pedagogy exercise their equal right with pupils vis-à-vis the truthfulness of learning material. In this sense, Saitou pedagogy is dialogic.

Compared with the theories of the dialogic pedagogy, the author argued that Saitou pedagogy is unique in its discovery of the teacher's possibility to learn new questions in pupils' learning material from pupils. Saitou pedagogy's focus on the teacher's questioning can open new fields of research in the dialogic pedagogy.

I focused on the relation between how pupils learn their learning material and how the teacher learns pupils' learning material. In other words, I focused on the epistemological aspect of the classroom lesson and argued that the lesson becomes dialogic when the teacher does not teach pupils the learning material one-sidedly, but the teacher learns something new and questions she/he did not know about pupils' learning material from pupils. On the other hand, we can focus not on the epistemological plane of the lesson but on the power relations in and surrounding the classroom lesson. Regarding the power to control the event of the lesson, pupils and the teacher do not have equal power in defining the classroom situation (Apple, 1979) because the teacher "holds most power" (Apple, 1979, p. 49). Teachers cannot execute their power freely, however. Instead, they are under the strong control of administrators of educational institutions. As the curriculum contents are controlled strictly by, in Japan, the central government, such power relations in the educational settings have some epistemological implications. 


\section{Dialogic Lessons and Triadic Relationship Among Pupils, Learning Topic, and Teacher}

Kiyotaka Miyazaki

What does Saitou pedagogy think of this topic? Kihaku Saitou considered the relation between education and politics. Saitou's view was that although teachers were helpless against political power, they could create something politics could not suppress. He wrote: Both art and education might be helpless against the brutal force of politics. Still, they can create something which the politics cannot suppress. That is why I have kept working as a teacher (Saitou, 1970b, p.127).

How would Saitou pedagogy develop without the constraint of the strict government control? Saitou pedagogy is not an application of any existing theory but a historical product of many practitioners' struggles for good lessons in the socio-historical situations given to the practitioners. Therefore, I posit that asking how it might develop in different socio-historical situations does not make much sense to ask. I cannot predict how the practitioners would respond in the different socio-historical situations and what kind of new characteristic would emerge as a result. However, asking such a question provides me with an opportunity to again consider the important characteristics of Saitou pedagogy, even though the answer itself does not make much sense. Thus, I present a brief discussion of this question.

The strict governmental control on education in Japan takes the form of the national guideline for course of study, which strictly determines which learning material is taught, in which grade, in what order. This strict control has been developing the mindset of teachers that the correct answers regarding the learning material are provided in a top-down manner. I found a notable example of this mindset in the FAQs of the website of the National Institute of Information and Communications Technology (1989). In this episode which occurred some 45 years ago, one elementary school student had a question if noon was 12 am or $0 \mathrm{pm}$. It would have provided a notable opportunity for the class to explore the topic, but the event did not develop that manner. The teacher, who did not know the answer, asked the principal, who did not know the answer either. Thus, the principal asked the town's board of education, which did not know the answer. The town's board asked the prefecture's board of education. The prefecture's board did not know the answer, so asked the Ministry of Education, Science and Technology (Ministry of Education in those days). However, the Ministry did not know the answer and, thus, asked the national organization of clock companies, which collaborated with the Horological Institute to conduct an investigation and decided, temporarily, that $0 \mathrm{pm}$ was better for the digital clocks than $12 \mathrm{am}$.

Saitou pedagogy has been struggling with this mindset of the teachers that supports, and is supported by, the strict guideline of the curriculum. In the struggle, it discovered that pupils can have their own questions, and the teacher can have her/his new question and discover pupils' unique questions in any learning material, even if the material is received from the top down. These questions are new and unique in the sense that they emerge in the lesson and based on the pupils' and the teacher's unique understanding of the material, and not necessarily the same as the question set from the curriculum builders, which defines one "correct" answer. Pupils and the teacher can have a deep and unique learning experience by exploring their unique questions during the lesson.

In other words, Saitou pedagogy's criticism of the national curriculum guideline can apply to any educational system, even a system in which the curriculum is created by pupils and teachers when the lesson does not develop from pupils' unique questions that have emerged, sometimes, from pupils' wrong or irrelevant' thoughts.

How would Saitou pedagogy develop without the constraint of the strict government control, then? My answer is: it would be basically the same as it is now. The teacher must create her/his curriculum by her/himself if no curriculum is provided. In this case, the new learning material is explored in an investigation of the unique questions that emerged in each unique lesson. The curriculum is not preplanned but the 


\section{Dialogic Lessons and Triadic Relationship Among Pupils, Learning Topic, and Teacher}

Kiyotaka Miyazaki

product of pupils' and the teacher's learning activities. Although it might be classifiable to the emergent curriculum, naming it so does not make much sense because it is not the product of an application of any theory of emergent curriculum and its actual form and characteristics are determined by the future teachers' practices $^{3}$.

Thus, what about the power relations between the pupils and the teacher? Teachers certainly have more power to organize the classroom situation than pupils. Thus, teachers have responsibilities to make the lesson dialogic for pupils. Saitou pedagogy posits that teachers fulfil their responsibility by learning the learning material authentically from pupils and discovering new questions regarding the learning material in pupils. As aforementioned, pupils can generate their own questions even in the learning materials allocated by the government and educational institutions. However, pupils are in most cases unaware of their questions different from teacher's or the curriculum's. For Saitou pedagogy, it is the teacher's responsibility to discover new questions in pupils, to make them explicit to the class and to make lessons dialogic.

There must be other means for the teacher to fulfill the responsibility to pupils. One means would be to set the ground rules for linguistic interactions in the classroom to secure the interpersonal relationship of mutual respect and trust, as Mercer and Wegerif have insisted. Whether setting rules explicitly or not, creating an interpersonal relationship of mutual respect and trust is needlessly important for the teacher. What does Saitou pedagogy think of this topic? Does it ignore it? Definitely not. For Saitou pedagogy, the teacher's ability to discover something new and significant in pupils' apparently wrong or irrelevant responses play a critical role even to establish the interpersonal relationships. The teacher can garner an authentic feeling of respect and trust when she/he can discover something significant in pupils' responses and say to pupils, "Oh you are great!" such as in the example lesson of Tsukamoto. Although setting the ground rules for linguistic interaction might be the presupposition to produce such mutual respect and trust, the teacher exists in the lesson only as its organizer as far as she/he sets the ground rules. The teacher also should and can exist in such a relationship of mutual respect and trust as a participant in the dialogue. The respect and trust shown by teachers can result in pupils respecting and trusting other pupils and the teacher.

One of the conditions for the teacher to be the dialogic participant is to discover something significant in pupils' responses; to do that, Saitou pedagogy posits that teachers should be an authentic learner. Apple (1993) pointed out a tendency he called proletarianization of teachers, where teachers are deprived of their autonomy and skills as teachers. Saitou pedagogy is teachers' effort to resist to this tendency and to be dialogic beings living with pupils.

\section{References}

Apple, M. W. (1979). Ideology and curriculum. New York, NY: Routledge Falmer.

Apple, M. W. (1993). Official knowledge: Democratic education in a conservative age. New York, NY: Routledge.

Arakida, M. (2013, Dec). Roku-nen-sei Kokugo: Kitsune no Mado [Sixth graders literature lesson: A Fox's Window]. Paper presented at the Winter meeting of Chiba-Ibaraki kyoujugaku no kai[ChibaIbaraki study group of the pedagogy]. Kujukuri, Chiba.

\footnotetext{
${ }^{3}$ The idea developed here is based on the discussion with Hirofumi Watahiki, a retired elementary school teacher who had studied and practiced Saitou pedagogy for years. The author thanks him for his valuable comments.
} 


\section{Dialogic Lessons and Triadic Relationship Among Pupils, Learning Topic, and Teacher}

Kiyotaka Miyazaki

Bakhtin, M. M. (1981). The dialogic imagination (C. Emerson \& M. Holquist, Trans.). Austin, TX: University of Texas Press.

Bakhtin, M. M. (1984). Problems of Dostoevsky's poetics (C. Emerson, Trans.). Minneapolis, MN: University of Minnesota Press.

Bakhtin, M. M. (1986). Speech genres and other late essays (V.W. McGee, Trans.). Austin, TX: University of Texas Press.

Brown, A. L., \& Campione, J. C. (1994). Guided discovery in a community of learners. In K. McGilly, (Ed.), Classroom lessons: Integrating cognitive theory and classroom practice (pp. 229-270). Cambridge, MA: MIT Press.

Bühler, K. (1934). Sprachtheorie. Jena, Germany: Fischer.

Burbules, N. C. (1993). Dialogue in teaching: Theory and practice. New York, NY: Teachers college press.

Burbules, N. C. (2006). Rethinking dialogue in networked spaces. Cultural studies $\leftrightarrow$ Critical methodologies, 6(1), 107-122. doi: 10.1177//1532708605282817

Du Bois, J. (2007). The stance triangle. In R. Englebretson (Ed.), Stancetaking in discourse: Subjectivity, evaluation, interaction. Amsterdam, Holland: John Benjamins.

Freire, P. (1994). Pedagogy of hope: Reliving Pedagogy of the oppressed (R. R. Barr, Trans.). London, UK: Continuum International Publishing.

Freire, P., \& Shor, I. (1987). A pedagogy for liberation: Dialogues on transforming education. Basingstoke, Hampshire: MacMillen Education.

Gadamer, H. G. (1975). Truth and method (J. Weinsheimer \& D.G. Marshall, Trans.). London, UK: Continuum.

Hosoya, J. (2001). Kyouka gakushu no shinrigaku [Psychology of subject matter learning]. Sendai, Japan: Tohoku Daigaku Shuppankai.

Kasahara, H. (1991). Hyouden Saitou Kihaku: Sono shigoto to ikikata [Critical biography of Kihaku Saitou: His works and life]. Tokyo, Japan: Ikkei - Shobou.

Linell, P. (2009). Rethinking language, mind, and world dialogically: Interactional and contextual theories of human sense- making. Charlotte, NC: Information age publishing INC.

Markova, I. (2003). Dialogicality and social representations: The dynamics of mind. Cambridge, UK: Cambridge University Press.

Markova, I. (2006). On 'the inner alter' in the dialogue. International journal of dialogical science. 1, 125147.

Matusov, E. (2009). Journey into dialogic pedagogy. Hauppauge, NY: Nova Science Publishers.

Matusov, E. (2011). Authorial teaching and learning. In E. J. White, \& M. A. Peters (Eds.), Bakhtinian pedagogy: Opportunities and challenges for research, policy and practice in education across the globe (pp. 21-46). New York, NY: Peter Lang.

Mercer, N. (1995). The guided construction of knowledge: Talk amongst teachers and learners. Clevedon, UK: Multilingual matters. 


\section{Dialogic Lessons and Triadic Relationship Among Pupils, Learning Topic, and Teacher}

Kiyotaka Miyazaki

Mercer, N., \& Littleton, K. (2007). Dialogue and the development of children's thinking: A sociocultural approach. London, UK: Routledge.

Miyazaki, K. (Ed.). (2005). Sougou-gakushu ha sikou-ryoku wo sodateru [Comprehensive learning fosters children's thought]. Tokyo, Japan: Ikkei-shobou.

Miyazaki, K. (2009). Kodomo no manabi kyoushi no manabi [Children's learning, teacher's learning]. Tokyo, Japan: Ikkei-shbou.

Miyazaki, K. (2014). From "unknown questions" begins a wonderful education: Kyozai-Kaishaku and the dialogic classroom. In K. Egan, A. Cant, \& G. Judson (Eds.), Wonder-full education: The centrality of wonder in teaching and learning across the curriculum (pp. 110-121). New York, NY: Routledge.

Moore, C., \& Dunham, P. J. (Eds.) (1995). Joint attention: its origins and roles in development. New York, NY: Lawrence Erlbaum.

National Institute of Information and Communications Technology. (1989). Gozen 12 ji or gogo 0 ji? [12 am or 0 pm?] Retrieved from http://jjy.nict.go.jp/QandA/FAQ/12am-or-0pm-J.html

Ongstad, S. (2004). Bakhtin's triadic epistemology and ideologies of dialogism. In F. Bostad, C. Brandist, L. Evansen, \& H. C. Faber (Eds.), Bakhtinian perspectives on language and culture: Meaning in language, art and new media (pp. 65-88). Hampshire, UK: Palgrave MacMillen.

Pearsall, J. \& Hanks, P. (Eds.). (2005). Oxford dictionary of English, Second edition revised. Oxford, UK: Oxford University Press.

Peirce, Ch. S. (1998). Charles S. Peirce: The essential writings. New York, NY: Prometheus Books.

Perret-Clermont, A. -N. (1980). Social Interaction and Cognitive Development. London, UK: Academic press.

Perret-Clermont, A. -N. (2015). The architecture of social relationships and thinking spaces for growth. In C. Psaltis, A. Gillespie, \& A.-N. Perret-Clermont (Eds.). Social relations in human and societal development. (pp. 51-70). London, UK: Palgrave MacMillan.

Rogoff, B. (1994). Developing understanding of the idea of communities of learners. Mind, Culture, and activity, 1(4), 209-229.

Rogoff, B., Turkanis, C. G., \& Bartlet, L. (Eds.). (2001). Learning together: Children and adults in a school community. New York, NY: Oxford University Press.

Rommetveit, R. (2003). On the role of "a psychology of the second person" in studies of meaning, language, and mind. Mind, culture, and activity, 10(3), 205-218.

Saitou, K. (1964). Jugyo no tenkai [Development of classroom lesson]. Tokyo, Japan: Kokudo-sha.

Saitou, K. (1970a). Kyouiku-gaku no susume [Recommending pedagogy]. Complete works of Kihaku Saitou, vol. 6, Tokyo, Japan: Kokudo-sha.

Saitou, K. (1970b). Hitotsu no kyoushi ron [A view of teachers]. Complete works of Kihaku Saitou, vol. 8, Tokyo, Japan: Kokudo-sha.

Saitou, K. (1975/1995). Jugyo to kyouzai-kaishaku [Classroom lesson and interpreting the teaching material]. Tokyo, Japan: Ikkei-shobou.

Sakuma, K. (1992). Shakai-ka nazotoki yusaburi itsutsu no jugyo [Five classroom lessons of questioning and shaking in social studies]. Tokyo, Japan: Gakuji-shuppan. 


\section{Dialogic Lessons and Triadic Relationship Among Pupils, Learning Topic, and Teacher}

Kiyotaka Miyazaki

Sawyer, R. K. (Ed.). (2014). The Cambridge handbook of the learning sciences. New York, NY: Cambridge University Press.

Schulman, L. S. (1986). Those who understand: Knowledge growth in teaching. Educational researcher, $15,4-14$.

Shibata, Y.(Ed.). (2009). Kyouka no honshitsu to jugyou: Minkan-kyouiku-undou no ayumi to Jissen [The essence of subject matter and the classroom lesson: The progress and the practices of Civil Education Movement]. Tokyo, Japan: Nihon-Hyoujun.

Tomasello, M., Carpenter, M., Call, J., Behne, T., \& Moll, H. (2005). Understanding and sharing intentions: The origins of cultural cognition. Behavioral and brain sciences, 28, 675-735. doi:10.1017/S0140525X05000129

Tomasello, M. (2014). A natural history of human thinking. Cambridge, MA: Harvard University Press.

Trevarthen, C., \& Hubley, P. (1978). Secondary intersubjectivity: Confidence, confiding and acts of meaning in the first year. In M. von Cranach, K, Foppa, W. Lepenies, \& D. Ploog (Eds.), Human ethology: Claims and limits of a new discipline. Cambridge, UK: Cambridge University Press.

Tsukamoto, Y. (2014). Kodomo wa kyoushi no "hatsumon" towa kotonaru "toi" wo motsu. [Children have different questions from "teacher posed question."]. Chiba-Keisai-Daigaku-Tanki-Daigaku-bu Kiyo [ the Proceedings of Chiba Keizai College], 10, 25-37.

Ueno, K. (2001). Kazu towa nanndarouka [What is a number?]. Sugaku Tushin [Mathematical report], 6(3), pp. 28-68.

Ushiyama, H. (2013). Kyoushi-kyouiku no jissenn kara mietekurukoto [What I learned in the practice of teacher education]. In T. Inagaki, \& H. Ushiyama, Zoku kyoushi-kyouiku no sozo [Creation of teacher education, second series] (pp. 138-166). Tokyo, Japan: Hyoron-sha.

Vygotsky, L. S. (1978). Mind and society: Development of higher mental processes. Cambridge, MA: Harvard University Press.

Wegerif, R. (2007). Dialogic education and technology: Expanding the space of learning. New York, NY: Springer.

Wells, G. (1999). Dialogic inquiry: Toward a sociocultural practice and theory of education. Cambridge, UK: Cambridge University Press.

Wells, G. (2000). Dialogic inquiry in education: Building on the legacy of Vygotsky. In C. D. Lee, \& P. Smagorinsky (Eds.), Vygotskian perspectives on literacy research: Constructing meaning through collaborative inquiry. Cambridge, UK: Cambridge University Press.

\section{(c)) EY}

New articles in this journal are licensed under a Creative Commons Attribution 4.0 United States License.

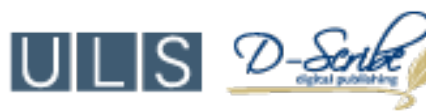

This journal is published by the University Library System, University of Pittsburgh as part of its D-Scribe 
Dialogic Lessons and Triadic Relationship Among Pupils, Learning Topic, and Teacher Kiyotaka Miyazaki

Digital Publishing Program and is cosponsored by the University of Pittsburgh Press. 